\title{
Tipificação da "reflexão de essência" constituidora da metafísica de Spinoza
}

\author{
Antônio Carlos da Rocha Costa ${ }^{1}$
}

Resumo: Este artigo apresenta uma extensão do modo hegeliano de caracterizar a progressão das reflexões de essência, de que Hegel se vale na "Ciência da Lógica" para introduzir sua noção de essência, produto de uma reflexão determinante. Tal modo estendido de caracterizar a progressão das reflexões de essência possibilita tipificar a reflexão de essência constituidora da metafísica de Spinoza, bem como dar indicações iniciais para a tipificação das reflexões de essência constituidoras das metafísicas de outros filósofos. $\mathrm{O}$ artigo conclui com a discussão de alguns aspectos da análise Hegeliana da filosofia de Spinoza, apresentada numa "Observação" incluída na $3^{\text {a }}$. seção da "Doutrina da Essência".

Palavras-chave: Hegel, Metafísica de Spinoza, Ciência da Lógica, Doutrina da Essência, Reflexões de Essência.

\section{Typing the "reflection of essence" constitutive of Spinoza's metaphysics}

\begin{abstract}
This paper presents an extension of the hegelian way of characterizing the progression of the reflection of essence, which Hegel makes use of in the "Science of Logic" to introduce his notion of essence, the product of a determining reflection. Such extended way of characterizing the progression of the reflections of essence allows for the typing of the reflection of essence that is constitutive of Spinoza's metaphysics. Also, it gives initial indications for typing the reflections of essence constitutive of the metaphysics of other philosophers. The paper ends with a discussion of some aspects of the hegelian analysis of Spinoza's philosophy, presented in a "Remark" included in the 3rd section of the "Doctrine of Essence".
\end{abstract}

Key-words: Hegel, Spinoza's Metaphysics, Science of Logic, Doctrine of Essence, Reflections of Essence.

${ }^{1}$ Doutor em Ciência da Computação (UFRGS, 1993). Mestrando em Filosofia, PPGFIL, PUCRS. Email: ac.rocha.costa@gmail.com 


\section{Introdução}

\subsection{Motivação}

A historiografia recente tem consagrado a noção de que o marxismo, na vertente desenvolvida por Louis Althusser e seus estudantes, tem forte influência, se não fundamento, na filosofia de Spinoza - ver, p.ex., os capítulos "The Sources of Louis Althusser's Spinozism" and "The Development of Althusser's Spinozism" em (Peden 2014).

Assim, parece ser um tópico de pesquisa interessante o de determinar os impactos que essa influência, e possível fundamentação, podem ter tido sobre a lógica que preside essa vertente do marxismo, inclusive em comparação com a vertente original, em que Marx ainda afirmava se valer do método hegeliano.

Em termos diretos, parece ser interessante tentar responder à pergunta: Qual o impacto da troca da filosofia de Hegel pela filosofia de Spinoza na lógica do materialismo dialético?

Para realizar tanto, é preciso ter claro, inicialmente, as diferenças lógicas entre as filosofias de Hegel e de Spinoza, para depois poder determinar os impactos da substituição de uma por outra, como referencial filosófico, na constituição daquela teoria.

Neste artigo, procuramos esclarecer uma dessas diferenças lógicas: a diferença entre o tipo de reflexão de essência constituinte da metafísica de Hegel e o tipo de reflexão de essência constituinte da metafísica de Spinoza.

Procedemos a essa diferenciação por meio da localização dos dois tipos de reflexão de essência na progressão da noção de reflexão de essência que Hegel apresenta no primeiro capítulo da primeira seção da "Doutrina da Essência", na "Ciência da Lógica". 


\subsection{Estrutura do artigo}

Na Seção 2, apresentamos de modo sumário os conceitos básicos da metafísica de Spinoza. Na Seção 3, definimos formalmente a operação que denominamos de reflexão de noções, apresentamos suas propriedades básicas. Na Seção 4, definimos formalmente a noção de configuração histórica de uma noção e introduzimos a noção de configuração histórica de uma progressão de noção.

$\mathrm{Na}$ Seção 4, fazemos uso das noções introduzidas anteriormente para caracterizar os diversos tipos de reflexão de essência que constituem as etapas da progressão da reflexão de essência.

Na Seção 5, analisamos o conceito hegeliano de configuração histórica de uma noção e estabelecemos os requisitos de um método para determinar essas configurações históricas. Na Seção 6, fazemos uso dessas noções para estabelecer formalmente a noção de configuração histórica de uma progressão de noções.

Na Seção 7, valendo-nos dos requisitos hegelianos para os métodos de determinação de configurações históricas de noções, apresentamos um esquema inicial da configuração histórica da progressão da reflexão de essência, onde procuramos caracterizar uma variedade de teorias metafísicas em função do tipo de reflexão de essência que as constitui.

Na Seção 8, mostramos a insuficiência dos critérios adotados por Hegel, em sua caracterização da progressão de reflexão de essência, para fins de tipificação da reflexão de essência constituinte da metafísica de Spinoza. Introduzimos, então, uma segunda dimensão tipificadora das reflexões de essência, possibilitando a tipificação da reflexão de essência spinozista, bem como seu posicionamento na progressão da reflexão de essência.

Na Seção 9, discutimos a "Observação", que Hegel incluiu no capítulo "O Absoluto", da "Doutrina da Ciência", comentando a filosofia spinozista. Mostramos que a análise de Hegel, se não 
confirma, pelo menos não invalida, a tipificação que fizemos da reflexão de essência que constitui a metafísica de Spinoza.

A Seção 10 é a Conclusão.

\section{conceitos básicos da metafísica de Spinoza}

Tomamos como resumo esquemático dos conceitos básicos da metafísica de Spinoza conforme sumariado em (Lord 2011), de onde extraímos a Tabela 1, adaptada e ampliada para os fins deste artigo.

\begin{tabular}{|c|c|c|c|c|c|c|}
\hline Substância & Atributos & $\Rightarrow$ & $\begin{array}{c}\text { Modos } \\
\text { infinitos } \\
\text { imediatos }\end{array}$ & $\begin{array}{c}\text { Modos } \\
\text { infinito } \\
s \\
\text { mediato } \\
\quad s\end{array}$ & $\begin{array}{c}\text { Modo } \\
s \\
\text { finito } \\
s\end{array}$ & \\
\hline \multirow[t]{2}{*}{$\begin{array}{c}\text { Natureza/De } \\
\text { us }\end{array}$} & Extensão & $\Rightarrow$ & $\begin{array}{l}\text { Movimen } \\
\text { to e } \\
\text { repouso } \\
\text { infinitos }\end{array}$ & $\begin{array}{l}\text { Indivíd } \\
\text { uo } \\
\text { físico } \\
\text { infinito }\end{array}$ & $\begin{array}{c}\text { Corpo } \\
\mathrm{S} \\
\text { físicos }\end{array}$ & $\begin{array}{c}\text { Modos de } \\
\text { extensão }\end{array}$ \\
\hline & $\begin{array}{c}\text { Pensamen } \\
\text { to }\end{array}$ & $\Longrightarrow$ & $\begin{array}{l}\text { Intelecto } \\
\text { infinito }\end{array}$ & $\begin{array}{c}\text { Indivíd } \\
\text { uo } \\
\text { pensant } \\
\text { e } \\
\text { infinito }\end{array}$ & $\begin{array}{c}\text { Ment } \\
\text { es }\end{array}$ & $\begin{array}{c}\text { Modos de } \\
\text { pensamen } \\
\text { to }\end{array}$ \\
\hline
\end{tabular}

Natureza geradora

Natureza gerada

Tabela 1: Esquema geral dos conceitos básicos da metafísica de Spinoza.

Descrevemos este quadro conforme segue:

- O quadro mostra que há cinco tipos principais de noções: substância, atributos, modos infinitos imediatos, modos infinitos mediatos e modos finitos.

- Substância é a noção de base, a partir da qual se derivam todas as demais. Substâncias são auto-subsistentes e eternas. 
- As essências das substâncias (substâncias podem ter mais de uma essência na metafísica de Spinoza) são atividades e as substâncias subsistem por meio de suas atividades essenciais. As atividades essenciais de uma substância são, portanto, eternas.

- Há apenas uma substância, que pode ser nomeada alternativamente como Natureza, Deus, ou Natureza/Deus.

- Substâncias são dotadas de atributos, que determinam as maneiras pelas quais as essências dessas substâncias são percebidas. Cada essência de uma substância se expressa através de um dos atributos da substância. A substância única Natureza/Deus é dotada de infinitas essências e, portanto, infinitos atributos para expressá-las.

- Cada essência expressa através de um atributo de uma substância se atualiza como um tipo de atividade, não como um tipo de ente. Essa atualização é expressão da atividade essencial da substância e é denominada um modo da substância.

- Da infinidade de atributos da única substância Natureza/Deus, a mente humana só percebe dois essencialmente, Extensão e Pensamento, aos quais correspondem apenas duas classes de modos: modos de extensão e modos de pensamento.

- As duas classes de modos de uma substância se distribuem sobre três tipos de modos: modos infinitos imediatos, modos infinitos mediatos e modos finitos.

- Modos infinitos imediatos são a expressão imediata da essência da substância Natureza/Deus, e na interpretação de (Lord 2011), constituem "leis e ordem dentro de um atributo" (p.15): a ordem infinita das relações físicas (i.e., dos movimentos e do repouso), no caso do atributo Extensão, e o intelecto infinito (i.e., a ordem infinita das ideias), no caso do atributo Pensamento. 
- Modos infinitos mediatos são a expressão da essência da substância Natureza/Deus tal como mediada pelos modos infinitos imediatos (p.15): o indivíduo físico infinito, que é a expressão da ordem infinita das relações físicas, e o indivíduo pensante infinito, que é a expressão do intelecto infinito.

- Modos finitos são a expressão da essência da substância Natureza/Deus tal como mediada pelos modos infinitos mediatos: corpos físicos, que são a expressão do indivíduo físico infinito, e mentes, que são a expressão do intelecto infinito.

A substância Natureza/Deus, seus atributos e seus modos relacionam-se, enquanto Natureza naturante (que indicamos no quadro acima como Natureza geradora) e Natureza naturada (que indicamos no quadro acima como Natureza gerada) conforme mostrado no quadro acima e conforme explicitado por Spinoza no trecho:

Por Natureza naturante nós devemos entender o que é em si mesmo e é concebido através de si mesmo, ou tais atributos de substância como expressa uma essência eterna infinita, quer dizer, Deus, na medida em que ele é considerado como uma causa livre. Mas por Natureza naturada eu entendo qualquer coisa que siga da necessidade da natureza de Deus, ou de qualquer dos atributos de Deus, quer dizer, todos os modos dos atributos de Deus na medida em que eles são considerados como coisas que estão em Deus, e que não podem ser nem ser concebidos sem Deus. (Spinoza XXX, p.YYY, E IP29S).

\section{A Noção genérica de "Reflexão DE NOÇÕES"}

A noção básica para compreensão da noção genérica do movimento nocional de reflexão é a noção da operação nocional de negação. 


\subsection{1 a operação de "Negação DE NOÇÕES"}

Uma negação é uma operação que leva de uma noção $A$ a uma noção $B$ que, de algum modo, se caracteriza como oposta a $A$.

Representamos a operação de negação que leva da noção $A$ para a noção oposta $B$ pelo esquema formalizado dado por $A \stackrel{\mathrm{Neg}}{\longrightarrow} B$.

Em função do caráter da relação de oposição nocional, em que se baseia a operação de negação, a operação de negação é inversível, de modo que $A \stackrel{\text { Neg }}{\longrightarrow} B$ se e somente se $B \stackrel{\text { Neg }}{\longrightarrow} A$.

Se $A \stackrel{N e g}{\longrightarrow} B$, dizemos que a noção $A$ está posta na noção $B$ e representamos esta afirmação por $A \sqsubseteq B$.

Pela propriedade de invertibilidade da operação de negação temos que:

3. $\quad$ Se $A \stackrel{N e g}{\longrightarrow} B$ então $A \sqsubseteq B$ e $B \sqsubseteq A$.

Isto é: se $A \stackrel{N e g}{\longrightarrow} B$ então a noção $A$ está posta na noção $B$ assim como a noção $B$ está posta na noção $A$.

\subsection{2 a operação de "Reflexão DE NOÇÕES"}

A operação de reflexão nocional é um tipo particular de operação de negação nocional: é uma operação de negação da forma $A \stackrel{N e g}{\longrightarrow} A$, em que a noção de chegada do movimento é igual à sua noção de partida.

Claramente, a operação de reflexão tem a propriedade da invertibilidade (inclusive porque a o reflexão é um caso particular da negação).

Por conveniência, também representamos a reflexão da noção $A$ por $A^{\text {v }}$.

Representando a oposição da noção $A$ por $\bar{A}$, podemos dizer, relativamente à operação de reflexão $A^{\cup}$ : 
2. $A \sqsubseteq A$

Isto é, a noção $A$ está posta em si mesma (pois $A^{\cup}$ é dado por $A \stackrel{N e g}{\longrightarrow} A$ ).

3. $\bar{A} \sqsubseteq A$

Isto é, a noção $A$ tem posta em si seu próprio oposto (exatamente pela mesma razão).

Claro está que a condição necessária para que a operação de reflexão de noções esteja bem definida é a de que a relação de oposição entre noções esteja bem definida nos casos reflexivos, e não se trivialize nos mesmos.

O esquema de progressão da "reflexão de essência" do Cap. 1 da "Doutrina da Essência" e suas configurações históricas

\section{3 elementos da noção hegeliana de "Essência"}

A essência é "a verdade do ser", "o que o ser é em si e para si" (p.31).

Mas as determinações da essência não estão na esfera do ser: "<sua> determinidade não é" (p.33).

As determinações da essência são postas na essência pela própria essência, por meio de operações de reflexão: são "determinações refletidas" (p.33).

\subsection{A Noção Genérica de "Reflexão de Essência"}

No Capítulo 1 da "Doutrina da Essência", Hegel desenvolve a noção de reflexão de essência, com base nas noções de essência e de aparecer.

Inicialmente, o aparecer em questão é o aparecer do ser, mas logo passa a considerar o aparecer da essência. 
Quando o aparecer em questão é o aparecer do ser, a essência é a negação desse aparecer. Denotando o aparecer do ser por aparecer [ser], temos que: aparecer [ser] $\stackrel{\mathrm{Neg}}{\longrightarrow}$ essência .

A invertibilidade da operação de negação, por outro lado, garante que também se tenha: essência $\stackrel{N e g}{\longrightarrow}$ aparecer [ser], de modo que, quando o aparecer em questão é o aparecer do ser:

4. aparecer $[$ ser $] \sqsubseteq$ essência

Isto é, o aparecer do ser está posto na essência (como aquilo de que ela é a essência).

5. essência $\sqsubseteq$ aparecer [ser]

Isto é, a essência está posta no aparecer do ser (como sua essência).

Quanto ao aparecer da própria essência, temos a situação que representamos por meio da expressão: aparecer [essência] $\stackrel{\mathrm{Neg}}{\longrightarrow}$ essência. Neste caso, vemos que:

6. aparecer [essência] $\sqsubseteq$ essência

Isto é, o aparecer da essência está posto na própria essência (a essência aparece dentro de si mesma).

7. $\quad$ essência ᄃ aparecer[essência]

Isto é, a essência está posta no aparecer da própria essência (ela é a essência de seu aparecer).

Por outro lado, no caso da reflexão de essência, denotado por essência ${ }^{\circlearrowright}$, temos que:

6. $\quad$ essência ᄃ

Isto é, a essência está posta na própria essência. 
Na proposição 6 determina: a essência é não apenas em si, ela também está nela mesma. Isto é, pela reflexão de essência, a essência também é para si.

A proposição 6 constitui o que Hegel denomina de reflexão ponente: a essência se põe a si mesma pela sua reflexão.

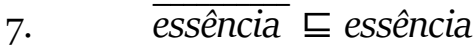

Isto é, o oposto da essência está posto na própria essência.

Na proposição 7, como o oposto da essência é o ser, a proposição significa que: o ser está posto na essência. Isto é, pela reflexão de essência, a essência se torna ser essencial, existência. (p.133)

\subsection{A Progressão da Reflexão de Essência}

No $1^{\circ}$. capítulo da primeira seção da "Doutrina da Essência", intitulado "A Aparência", a noção genérica de reflexão de essência, discutida na subseção anterior, ganha um desenvolvimento progressivo cujas etapas a vão determinando em grau crescente.

$\mathrm{Na}$ Tabela 2, listamos as quatro etapas dessa progressão da reflexão de essência.

Progressão da reflexão de essência

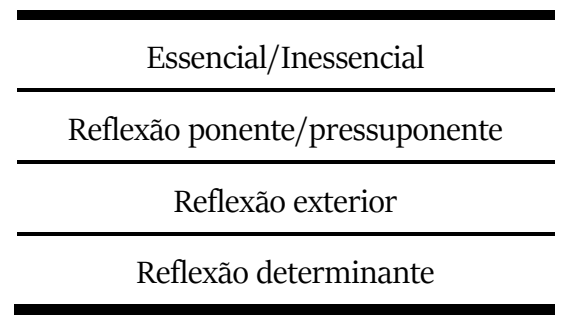

Tabela 2: A progressão da reflexão de essência. 
Na primeira linha, incluímos a etapa da progressão em que a essência é determinada como o essencial, embora esta seja uma etapa pré-reflexiva, posto que a reflexão de essência inicia efetivamente com a etapa de reflexão ponente/pressuponente.

No que segue, comentamos brevemente as características de cada uma dessas etapas.

\subsubsection{O Essencial e o Inessencial}

A etapa pré-reflexiva do desenvolvimento da noção de essência é caracterizada pelo fato de que "em um ser aí são diferenciados um do outro um essencial e um inessencial", mas de modo tal que "essa diferença é um pôr exterior", "um isolamento de uma parte do ser aí em relação à outra parte do mesmo", realizado de um modo em que esse "isolamento não toca na próprio ser aí", sendo "uma separação que cai em um terceiro". (p.38)

Em outros termos, um essencial é uma parte do ser aí que foi destacada como tal, como "essencial" nesse ser aí, frente ao resto desse ser aí, destacado como inessencial a esse ser aí.

Os fatos determinantes dessa caracterização são, portanto, que:

- a parte destacada como essencial está dada no ser aí em questão;

- essa parte é destacada, e determinada como essencial, por um terceiro, não pelo ser aí mesmo ("não toca nele").

Desse modo, "fica indeterminado o que pertence ao essencial ou ao inessencial" e "o que constitui sua diferença são um aspecto e uma consideração externos quaisquer". (p.38)

Como resultado, no ser aí em questão, é completamente indiferente o que termina sendo considerado essencial e o que termina sendo inessencial: "o mesmo conteúdo <i.e., a mesma parte do ser aí>, pode ser visto ora como essencial, ora como inessencial". (p.38) 
Essencial, portanto, é um termo técnico, com uma definição precisa, nessa consideração de Hegel. Ele designa o resultado dessa determinação não necessária de uma parte de um ser aí como essencial. Desse modo, não se confunde com o uso cotidiano desse termo, onde frequentemente é usado, indiferentemente, para designar o que Hegel designaria propriamente como uma essência.

Essência ocorre apenas onde há reflexão de essência, portanto, apenas nas etapas seguintes da progressão dessa noção; nas quais, então, o essencial não ocorre.

Representamos o modo de operação dessa etapa não-reflexiva da progressão da reflexão de essência pela Figura 1, onde a seta pontilhada indica a operação de escolha do essencial, por parte de um sujeito, e a seta tracejada indica o modo pelo qual o essencial escolhido determina o restante do ser aí, tomado então como inessencial.
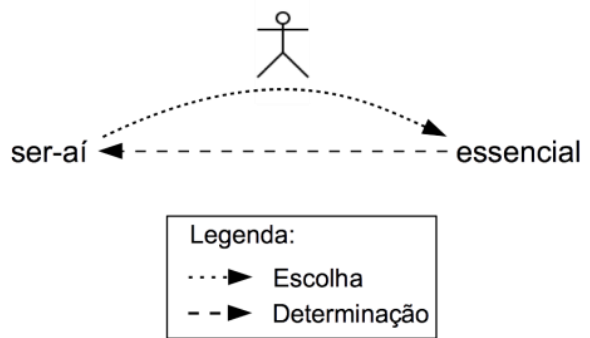

Fig. 1: Esquema da primeira etapa da progressão da reflexão de essência: essencial/inessencial.

\subsubsection{A Reflexão Ponente/Pressuponente}

A reflexão ponente/pressuponente inicia a fase propriamente reflexiva do desenvolvimento da noção de essência.

Usamos o temo combinado ponente/pressuponente para designar este tipo de reflexão de essência (e não o termo simples ponente, como faz Hegel no título do item do capítulo em que a caracteriza), porque a condição de a reflexão de essência desta etapa ter o caráter pressuponente é crucial para o entendimento da mesma. 
O fato de a reflexão ser ponente significa que ela é uma reflexão que põe a essência que está refletindo. O fato de a reflexão ser pressuponente, por outro lado, significa que ela pressupõe (ou, pré-põe) aquilo cuja essência está pondo e refletindo.

A reflexão ponente/pressuponente, característica desta primeira etapa reflexiva da progressão da noção de reflexão de essência, combina então essas duas características: pôr a essência que vai refletir, e pré-pôr aquilo de que essa essência é essência.

A reflexão <ponente/pressuponente>, portanto, encontra diante dela um imediato <a essência que ela põe>, além do qual ela vai $<$ em direção ao que ela põe > e a partir do qual ela é o retorno <em direção à essência que ela põe >. Mas este retorno é somente o pressupor do que foi encontrado <isto é, do que foi pré-posto>. Este último devém somente no fato de ele ser abandonado <i.é, pré-posto >. (p.45)

Finalmente, Hegel caracteriza o imediato que é pré-posto pela reflexão ponente/pressuponente como como aparência e como ser posto, isto é, uma aparência à qual se atribuiu ser:
A reflexão <ponente/pressuponente> <...> é a essência que aparece dentro dela mesma <i.é, que é posta> e pressupõe-se apenas a aparência, o ser posto $<\ldots>$. (p.46)

Resumindo

a terminologia,

na

reflexão ponente/pressuponente:

- A reflexão ponente põe a essência.

- A reflexão pressuponente pressupõe a aparência.

- A aparência, que é pressuposta, é pressuposta como ser posto.

Representamos o modo de operação da reflexão ponente/pressuponente pela Figura 2, onde indicamos separadamente os dois momentos dessa reflexão, o momento da pressuposição e o momento da posição. 

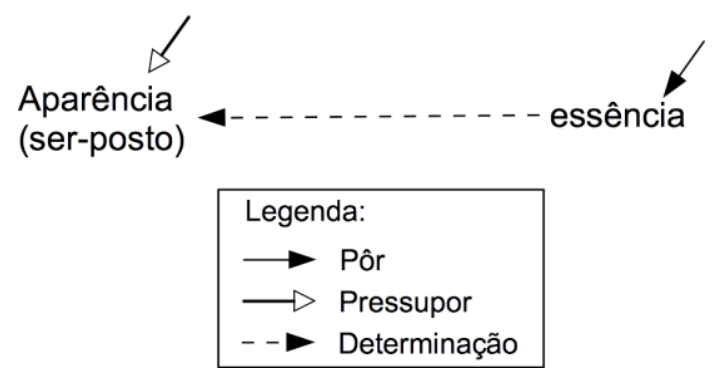

Fig. 2: Esquema da segunda etapa da progressão da reflexão de essência: reflexão ponente/pressuponente.

\subsubsection{A Reflexão exterior}

A reflexão exterior constitui a terceira etapa da progressão da reflexão de essência.

A principal diferença entre a reflexão exterior e a reflexão ponente/pressuponente está no seguinte. Na reflexão ponente/pressuponente, a aparência tem o caráter de um ser posto, um ser que é posto pela própria reflexão.

Já na reflexão exterior, a aparência não tem o caráter de ser posto, mas sim o de negativo da própria reflexão. Isto é, na reflexão exterior, a aparência tem o caráter do outro da reflexão, o caráter do que tem subsistência independente da subsistência da reflexão.

$<A$ reflexão exterior $>$ está duplicada, uma vez enquanto pressuposto ou reflexão dentro de si $<o$ imediato pressuposto, como na reflexão pressuponente>. Outra vez, ela é enquanto reflexão que se relaciona negativamente consigo; ela se relaciona consigo como com aquele seu não ser <i.é, tomando a essência como o não ser da aparência> (p.46)

Nessa dupla condição, de levar em conta tanto o imediato (i.é, a aparência que ela encontra como subsistente), quanto a essência (que ela põe como o outro do imediato), resulta que a essência que 
a reflexão exterior determina e põe nesse imediato é uma composição desses dois componentes.

Ao imediato que é determinado por essa composição de imediatidade encontrada, e essência tomada como o outro do imediato e como reflexão dentro de si, Hegel chama de imediato determinado:

Essa reflexão exterior é o silogismo no qual estão os dois extremos, o imediato e a reflexão dentro de si; o termo médio do mesmo é a relação de ambos, o imediato determinado, de modo que uma parte do mesmo, a imediatidade, compete somente a um extremo $<$ i.é, imediato encontrado $>$; a outra parte, a determinidade $<\ldots$. , somente ao outro extremo <i.é, à essência tomada como o outro do imediato >. (p.47)

Esta reflexão é denominada externa porque o caráter de negação da essência posta pela reflexão, tomada desse modo como o outro da imediatidade, faz com que as determinações que esta reflexão põe nesta imediatidade sejam externas a esta última, justamente por não serem derivadas plenamente dessa imediatidade, mas sim - em parte - do outro dessa imediatidade, isto é, a essência posta pela reflexão.

$\mathrm{O}$ acesso ao imediato, tomado como ser posto, não pode ser realizado pela própria reflexão, já que aquele imediato é o outro da reflexão. Tal acesso exige o concurso de um outro tipo de operação, nomeadamente, a intuição. A reflexão exterior só pode ocorrer com a intervenção de um sujeito capaz de intuição, assim como de reflexão. De modo que, com isso, o sujeito se torna indispensável para a reflexão exterior.

Representamos, na Figura 3, o esquema de operação da reflexão exterior. Procuramos mostrar explicitamente que tanto o acesso ao imediato que é em si, quanto a determinação do mesmo pela essência-termo-médio que resulta da reflexão exterior, requerem a intervenção do sujeito. A seta circular representa o silogismo, a operação produtora da essência-termo-médio. 

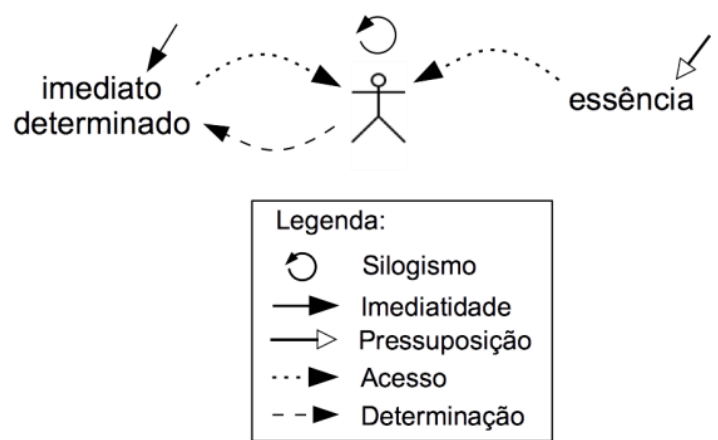

Fig. 3: Esquema da terceira etapa da progressão da reflexão de essência: reflexão exterior.

\subsubsection{A Reflexão Determinante}

A quarta, e última, etapa da progressão da reflexão de essência é constituída pela reflexão determinante, que é a reflexão "plenamente realizada" (p.49).

A reflexão determinante é em geral a unidade da reflexão ponente e da reflexão exterior. (p.49)

onde, por reflexão ponente, deve-se entender aqui a reflexão apenas ponente, não mais a reflexão ponente/pressuponente.

A <parte correspondente à> reflexão exterior inicia do ser imediato, a <parte correspondente à > reflexão ponente, do nada. (p.49)

O ser imediato de que inicia a parte correspondente à reflexão exterior é aquele que é pressuposto por ela, e que é tomado como $o$ outro da reflexão.

A parte correspondente à reflexão ponente inicia do nada porque é no nada que ela põe a essência com que ela vai determinar o ser imediato. 
Mas, aqui, essas duas reflexões estão em unidade, na reflexão determinante, o que modifica a de modo crucial a natureza de seus resultados:

8. A essência, que antes era posta pela reflexão ponente como o outro do imediato, torna-se agora alto-subsistente, na forma das essencialidades (as determinações de reflexão).

9. O imediato, que antes era posto como determinado externamente, torna-se agora o imediato determinado, isto é, o imediato determinado de modo essencial por meio de suas essencialidades.

O seguinte passo, em que a reflexão exterior se torna um pressupor absoluto do imediato, leva à modificação do resultado da reflexão ponente, modificação pela qual a essência, que anteriormente era apenas posta por esta reflexão ponente (sendo, portanto, dependente do sujeito que sustentava tal reflexão), tornase agora essência auto-subsistente, no contexto da unidade formada pelas duas reflexões na reflexão determinante:

Mas o pôr < da essência pela reflexão ponente> está agora em unidade com a reflexão exterior; dentro dessa unidade, a reflexão exterior é um pressupor absoluto <do imediato $>$, quer dizer, o repelir de si mesmo da reflexão <i.é, a essência, enquanto negação do imediato, torna-se independente da reflexão >, ou seja, o pôr da determinidade como pôr dela mesma <quer dizer, o pôr da essência como auto-posição e, portanto, como auto-subsistência> . (p.5o)

\section{A noção de "configuração histórica" de um conceito e $\mathbf{O}$ método de determinação das configurações históricas de um conceito}

Por configuração histórica de um conceito entendemos o modo como um conceito aparece em sua existência exterior, isto é, 
na temporalidade e na historicidade a que a consciência acede de modo imediato:

De lo que se trata, entonces, es de reconocer en la apariencia de lo temporal y pasajero la substancia, que es imanente, y lo eterno, que es presente. Pues lo racional, que es sinónimo de la idea, en la medida en que con su realidad entra al mismo tiempo en la existencia exterior, se despliega en una riqueza infinita de formas, fenómenos y configuraciones, y recubre su núcleo con la corteza multicolor en la que en un primer momento habita la consciencia $<\ldots>$. (p.51)

Hegel distingue entre a configuração histórica de um conceito e a configuração do conceito enquanto configuração atemporal que o conceito assume como momento da ideia que lhe corresponde (a qual denominamos aqui de configuração conceptual):

La configuración que se da el concepto en su realización es, para el conocimineto del concepto mismo, el momento esencial de la idea, que difiere de su forma de ser sólo como concepto. (p.55)

Quanto ao método de determinação de uma configuração conceptual e suas correspondentes configurações históricas, Hegel estabelece como requisito o de determinar inicialmente a configuração conceptual e, apenas posteriormente, suas configurações históricas (HEGEL 1988):

En el conocimento filosófico <e em seu método > la necessidade de un concepto es lo principal, y el camino que se presenta como el resultado de un devenir constitue su demonstración y deducción. Si el contenido es por si necesario, el segundo paso consistirá entonces en buscar qué le corresponde en la representación y el lenguaje <i.é, sua configuração histórica em um momento histórico dado >. (p.57)

Nessa determinação de uma configuração histórica de um conceito, Hegel não descarta a possibilidade do uso de conceitos do entendimento. Ao contrário, admite a possibilidade de elevar 
conceitos do entendimento ao estatuto de formas de configurações conceituais de conceitos, se a representação tem, por conteúdo, um conteúdo verdadeiro (HEGEL 1988):

Si la representación no es también falsa en quanto a su contenido, se pude perfectamente mostrar cómo el concepto está incluído y presente en ella de un modo esencial; en otras palabras, la representación pude ser elevada a la forma del concepto. Pero no puede ser de ninguna manera medida y criterio del concepto por si mismo necesario y verdadero, sino que, por el contrario, debe tomar de éste su verdad, y rectificarse y conocerse a partir de él. (p.57)

\section{Configuração histórica da progressão de uma noção}

Nesta seção, fazemos uso da distinção entre as noções de configuração conceptual e de configuração histórica de um conceito (Seção 5), e dos requisitos dos métodos de determinação das mesmas (Seção 6), para estabelecer a noção de configuração histórica da progressão de uma noção:

10. Chamamos de configuração histórica da progressão de uma noção à sucessão de configurações históricas que essa noção adquiriu ao longo da história.

A Figura 4 ilustra a noção de configuração histórica de progressão de noção mostrando as progressões históricas de duas noções quaisquer, $N_{1}$ e $N_{2}$ (consideradas independentes uma da outra, neste exemplo). A linha TH é uma linha de tempo, onde se indicam os tempos históricos em que ocorreram as configurações históricas das noções que estão em questão.

As progressões dessas noções são dadas, respectivamente, pelas sequências de configurações conceptuais que essas noções adquiriram ao logo de suas respectivas progressões: 


$$
\begin{aligned}
& \text { - Progressão }\left[N_{1}\right]=\left(N_{1}^{1}, N_{1}^{2}, N_{1}^{3}, N_{1}^{4}\right) \\
& \text { - Progressão }\left[N_{2}\right]=\left(N_{2}^{1}, N_{2}^{2}, N_{2}^{3}\right)
\end{aligned}
$$

Cada configuração conceptual podendo ocorrer em diferentes tempos históricos, indicamos como nos exemplos que seguem o conjunto de tempos históricos em que uma configuração conceptual ocorreu:

$$
\begin{aligned}
& -T H\left[N_{1}^{1}\right]=\left\{t_{1}\right\} \\
& \text { - } T H\left[N_{2}^{3}\right]=\left\{t_{4}, t_{6}\right\}
\end{aligned}
$$

A configuração histórica da progressão de uma noção é dada pela sequência de ocorrências de suas configurações conceptuais:

- ConfigHist $\left[N_{1}\right]=\left(N_{1}^{1}, N_{1}^{3}, N_{1}^{2}, N_{1}^{4}\right)$

- ConfigHist $\left[N_{2}\right]=\left(N_{2}^{1}, N_{2}^{3}\right)$

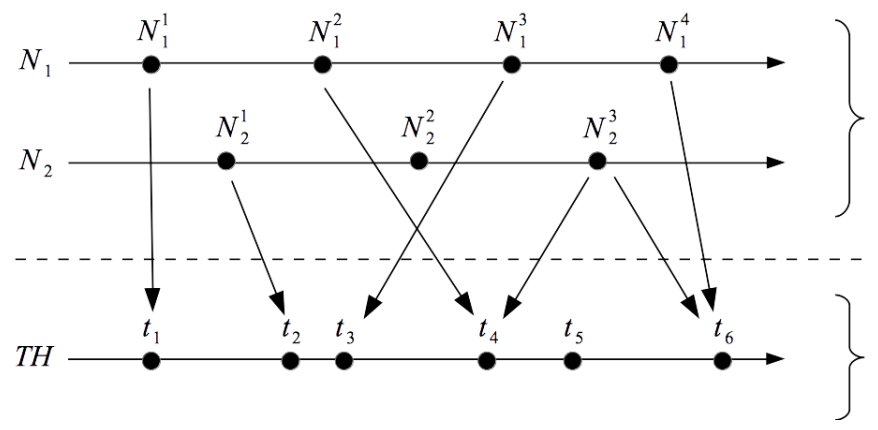

Esfera das Progressões de Noções

Figura 4: Configuração histórica da progressão de duas noções.

\section{Uma observação:}

Note-se que a noção de configuração histórica da progressão de uma noção está definida aqui de modo bastante genérico. Assim, é compatível com essa definição: 
- uma noção não apresentar configuração histórica para alguma configuração conceptual de sua progressão: p.ex., na Fig.4, $N_{2}^{2}$ não teve configuração histórica, de modo que $T H\left[N_{2}^{2}\right]=\{\}$.

- uma particular configuração conceptual de uma noção ter como configuração histórica correspondente uma configuração histórica que ocorreu anteriormente à configuração histórica de uma configuração conceptual que lhe é precedente, na progressão da noção: p.ex., na Fig. 4, $\mathrm{TH}\left[\mathrm{N}_{1}^{3}\right]=\left\{\mathrm{t}_{3}\right\}$ e $T H\left[N_{1}^{2}\right]=\left\{t_{4}\right\}$.

- configurações históricas de noções independentes ocorrerem simultaneamente no mesmo momento histórico: p.ex., na Fig. 4, $t_{6}$ é um tempo histórico em que ocorrem tanto a configuração conceptual $\mathrm{N}_{1}^{4}$ quanto a configuração conceptual $\mathrm{N}_{2}^{2}$.

Deixamos indeterminada, aqui, o quanto da generalidade que adotamos na definição acima é necessária a uma apresentação formal adequada do modo como Hegel pensa a questão das configurações históricas da progressão dos conceitos.

O que segue não faz uso dessa generalidade ampla. Em particular, no caso da progressão da noção de reflexão de essência, examinado a seguir, não há antecipação de configurações históricas, relativamente à ordem de progressão das configurações conceptuais da noção que está em questão. Porém, fazemos uso da possibilidade de ocorrência de múltiplas configurações históricas para a mesma reflexão de essência.

Note-se, finalmente, que o fato de uma configuração conceptual ocorrer, em um dado momento histórico, através de uma determinada configuração histórica, não significa que essa 


\section{Um esquema preliminar para a conFiguração Histórica da progressão da Reflexão de Essência}

Apresentamos, agora, um esquema preliminar para a configuração histórica da progressão da reflexão de essência, que nos permite identificar o tipo de reflexão de essência que nos parece próprio da metafísica de Spinoza.

A primeira coluna da Tabela 2 lista as configurações conceptuais constituintes da progressão da reflexão de essência (chamando-as de tipos de reflexão de essência, cf. Tab. 1). A segunda coluna da Tabela 2 relaciona, em cada linha, a configuração conceptual indicada na linha a uma configuração histórica que julgamos capaz de caracterizar a ocorrência histórica daquela configuração conceptual.

Justificamos a seguir, de forma preliminar, o relacionamento entre os tipos de reflexão de essência e as configurações históricas que está mostrado na Tabela 3.

\begin{tabular}{l|l} 
Tipo de reflexão de essência & Configuração histórica \\
\hline Essencial/Inessencial & Pré-Socráticos Jônicos \\
\hline Ponente/pressuponente & Platão \\
\hline Exterior & Kant \\
\hline Determinante & Hegel \\
\hline
\end{tabular}

Tabela 3: A configuração histórica da progressão de reflexão de essência.

\subsection{Essencial/Inessencial}

Como visto na Seção 4.3.1, a etapa inicial da progressão da reflexão de essência não é, propriamente, reflexiva. Nesta etapa, o essencial é apenas um algo, escolhido de modo indiferente no ser aí 
imediato, em contraposição ao resto, tomado então como inessencial:

A diferença entre o essencial e o inessencial fez recair a essência na esfera do ser aí, na medida em que a essência, como ela é inicialmente <i.é, nesta etapa da progressão $>$, está determinada como imediata, como algo que é $\langle\ldots .$. . A esfera do ser aí está assim colocada como fundamento $<\ldots .>$. (p.38)

Na medida em que, portanto, em um ser aí são diferenciados um do outro um essencial e um inessencial, essa diferença é um pôr exterior <i.é, um pôr realizado por um sujeito externo>, um isolamento de uma parte do ser aí em relação à outra parte do mesmo, isolamento que não toca no próprio ser aí <i.é, que não entra no ser aí, em direção à sua essência> - uma separação que cai em um terceiro. (p.38).

Parece-nos que esse tipo de reflexão de essência, distinguindo o essencial do inessencial com base em uma escolha indiferente de um algo no ser aí imediato, constitui o procedimento de determinação de essência típico do pensamento pré-socrático, especialmente o pensamento jônico.

Para alguns desses filósofos, o essencial é a água; para outros, a terra; ou o ar; ou o fogo. Para outros ainda, uma composição desses. Cada essencial desses é tomado do conjunto de elementos disponíveis imediatamente no ser aí com base numa preferência de ordem pessoal do filósofo, sem constituírem produto da reflexão.

Por isso mesmo a variedade de possibilidades e a falta de determinação racional de qual deles é, efetivamente, o essencial:

Nesse caso, fica indeterminado o que pertence ao essencial ou ao inessencial. O que constitui sua diferença são um aspecto e uma consideração externos quaisquer, e o mesmo conteúdo, por causa disso, precisa ser visto ora como essencial, ora como inessencial. (p.38) 


\subsection{Reflexão Ponente/Pressuponente}

Platão é, reconhecidamente, o primeiro a pensar a verdade do ser a partir da noção de essência e, como visto na Seção 4.3.2, é com a reflexão ponente/pressuponente que inicia propriamente a progressão da reflexão de essência, com seu caráter reflexivo.

A reflexão ponente/pressuponente, no seu movimento ponente, põe a essência, e no seu movimento pressuponente, pressupõe aquilo que essa essência determina.

Pensamos que esta é uma caraterização adequada para o tipo de reflexão de essência que constitui a metafísica platônica: Platão põe inicialmente a essência, na forma do Bem supremo e do mundo das ideias que lhe correspondem, e pressupõe, como subjacente ao ser aí imediato, a matéria informe (que é então conformada, pelo Demiurgo, com base nas ideias presentes naquele mundo).

\subsection{Reflexão Exterior}

Como visto na Seção 4.3.3, a reflexão exterior confronta o imediato e essência que ela reflete, e realiza um silogismo entre os dois, determinando como resultado um termo médio, que relaciona ambos.

Pensamos que esta é uma caracterização adequada para o tipo de reflexão de essência que constitui a lógica transcendental de Kant: da relação silogística (i.e., sintética) entre o imediato (os objetos da intuição) e a essência refletida (as categorias e os princípios do entendimento) resulta o termo médio, constituído pelos objetos da natureza e suas relações.

\subsection{Reflexão Determinante}

Como visto na Seção 4.3.4, a reflexão determinante é a forma completa da reflexão de essência. 
O segundo capítulo da primeira seção da "Doutrina da Essência", intitulado "As essencialidades ou as determinações de reflexão", mostra que a reflexão determinante constitui as determinações de reflexão (ou, essencialidades) com as quais se determina, de modo básico, o ser aí: identidade, diferença, igualdade, desigualdade, oposição, contradição.

Essas determinações de reflexão constituem a base do conteúdo conceptual com o qual a ideia realiza o núcleo essencial do ser aí, inclusive em seu caráter contraditório fundamental.

\section{A insuficiência DO esquema HEGELIANO de progressão DA "REFLEXÃO DE ESSÊNCIA", e suas configurações históricas, para a determinação do tipo da "reflexão de essência" da metafísica de Spinoza.}

Historicamente, Spinoza situa-se entre Platão e Kant, o que sugeriria, talvez, que sua metafísica, tal como apresentada de modo elementar na Seção 2, poderia ter como constituinte um tipo de reflexão de essência intermediário entre o tipo reflexão ponente/pressuponente e o tipo reflexão exterior (ver Tabela 4).

\begin{tabular}{c|c} 
Tipo de reflexão de essência & Configuração histórica \\
\hline Essencial/Inessencial & Pré-Socráticos Jônicos \\
\hline Ponente/pressuponente & Platão \\
\hline Exterior & Kant \\
\hline Determinante & Hegel
\end{tabular}

Tabela 4: a posição histórica de Spinoza, na progressão da reflexão de essência.

Nesta seção, porém, argumentamos que a reflexão de essência constituinte da metafísica de Spinoza é melhor entendida, inicialmente, como uma combinação de aspectos das reflexões de 
essência do tipo essencial/inessencial e do tipo reflexão ponente/pressuponente.

A reflexão de essência constituinte da metafísica de Spinoza tem aspectos relevantes da reflexão de essência do tipo pressuponente porque ela pressupõe a substância Deus/Natureza, assim como a metafísica de Platão pressupõe a matéria indeterminada.

Por outro lado, a metafísica de Spinoza tem aspectos relevantes da reflexão de essência do tipo essencial/inessencial porque, uma posta a substância Deus/Natureza, ela estabelece que essa substância é o essencial do ser aí, e que tudo o que aparece de modo imediato é inessencial.

Mais ainda, a metafísica de Spinoza, como a metafísica présocrática, assume que tudo o que aparece de modo imediato é gerado pela substância Deus/Natureza, de modo análogo ao que a metafísica pré-socrática considera que todo ente é gerado pelo elemento essencial escolhido (ou por uma combinação de elementos essenciais, se esta for a opção feita pelo filósofo).

Com essa caracterização, porém, vemos que não é possível localizar adequadamente o tipo de reflexão de essência que constitui a metafísica de Spinoza na progressão da reflexão de essência.

\section{uma segunda dimensão para o esquema de progressão da "reflexão de essência" e a Tipificação da "reflexão de essência" constituidora da metafísica de Spinoza}

A solução que encontramos para possibilitar o enquadramento do tipo de reflexão de essência constituinte da metafísica de Spinoza na progressão da reflexão de essência foi reconstruir essa progressão, no seguinte modo:

- por um lado, consideramos que a progressão da reflexão de essência apresentada por Hegel tem por base uma dimensão que (apenas por comodidade) denominamos de 
dimensão da complexidade conceptual da reflexão de essência: dizemos que quanto mais avançado um tipo de reflexão de essência se encontra na progressão, maior é sua complexidade conceptual;

- por outro lado, consideramos que uma segunda dimensão relevante das reflexões de essência distingue entre reflexões de essência que têm caráter gerador e reflexões de essência que têm caráter conformador.

O resultado que obtemos está mostrado na Tabela 5. Na primeira coluna da Tabela 4, mantemos a denominação "Tipo de reflexão" para indicar a coluna que ordena os tipos de reflexão de essência conforme a complexidade conceptual dos mesmos.

A segunda coluna da Tabela 4 determina os tipos de reflexão de essência mostrados em termos de sua característica geradora ou conformadora. Para tanto, dividimos essa segunda coluna em duas subcolunas, denominadas "Reflexão geradora" e "Reflexão conformadora", respectivamente.

\begin{tabular}{c|c|c|} 
Tipo de reflexão & Reflexão geradora & $\begin{array}{c}\text { Reflexão } \\
\text { conformadora }\end{array}$ \\
\hline Essencial/Inessencial & $\begin{array}{c}\text { Pré-Socráticos } \\
\text { Jônicos }\end{array}$ & Aristóteles \\
\hline Ponente/Pressuponente & SPINOZA & Platão \\
\hline Exterior & Hume & Kant \\
\hline Determinante & \multicolumn{2}{|c|}{ Hegel? } \\
\hline
\end{tabular}

Tabela 5: a progressão da reflexão de essência com duas dimensões. 
Claramente, temos a seguinte classificação das configurações históricas da reflexão de essência, conforme seu caráter gerador ou conformador *:

- Metafísica Pré-Socrática: reflexão de essência geradora, porque todo ente é gerado por uma concentração do elemento essencial, ou por uma combinação de elementos essenciais;

- Metafísica de Platão: reflexão de essência conformadora, porque as ideias servem à conformação da matéria indeterminada;

- Metafísica de Kant: reflexão de essência conformadora, porque as categorias e os princípios do entendimento servem à conformação dos objetos da intuição e suas relações.

Claramente, também, a metafísica de Spinoza é constituída por uma reflexão de essência que, além do caráter de caráter de reflexão geradora, conforme discutido na Seção 9, tem também o caráter de reflexão pressuponente, conforme discutido na Seção 2 e evidenciado na Tabela 1. Daí o lugar que ela ocupa na Tabela 5.

Na Seção 12, discutimos o modo como Hegel determina o caráter da reflexão de essência constituinte da metafísica de Spinoza.

\section{Tipificação de reflexões de essência constituidoras de outras metafísicas}

A introdução da segunda dimensão das reflexões de essência, relativa ao caráter gerador ou conformador das mesmas, abre espaço para a classificação de outras configurações históricas de

\footnotetext{
* Não está no escopo deste artigo uma análise fundamentada das metafísicas que serão examinadas. Por isso, em relação a cada uma, nos limitamos à análise das versões esquemáticas dessas metafísicas, presentes no senso comum. Cremos, porém, que as análises apresentadas são suficientes para ilustrar a possibilidade de identificação metódica da reflexão de essência constituidora de qualquer metafísica.
} 
outras metafísicas, em função dos tipos de reflexão de essência que as constituíram.

Assim, temos as seguintes classificações adicionais:

- Metafísica de Aristóteles: do tipo conformadora (posto que para Aristóteles a essência é a forma do ente) e do tipo présocrático essencial/inessencial (posto que os entes são pensados como constituídos por matéria e forma; e enquanto componentes dos entes, as formas são determinadas por Aristóteles como o essencial, em contraposição à matéria, determinada como o inessencial);

- Metafísica empirista (representada por Hume, na Tabela 5): do tipo reflexão exterior e gerador (posto que toma o imediato como dado e as estruturas cognitivas do sujeito como geradora das qualidades essenciais dos entes);

Ficamos, então, com o problema de como classificar a reflexão determinante, constituinte da metafísica de Hegel, quanto ao caráter gerador ou conformador da mesma. Neste artigo, deixamos tal problema em aberto.

\section{Discussão II: A Observação de hegel sobre a filosofia spinozista, na $3^{\mathrm{a}}$. Seção da "DOUTRINA DA ESSÊNCIA"}

No primeiro capítulo da 3a. seção da "Doutrina da Essência", Hegel insere uma "Observação" sobre as filosofias spinozista e leibniziana (pp.200-204). Esta "Observação" deve ser lida no contexto do capítulo em que ela está inserida, intitulado "O Absoluto".

Por questão de espaço, não podemos apresentar aqui um resumo do conteúdo desse capítulo. Mas, para a finalidade da presente seção, é suficiente indicar que, em tal capitulo, Hegel caracteriza a reflexão do absoluto, que ele designa como exposição 
do absoluto, em termos análogos àqueles com que Spinoza caracteriza a exposição da substância Deus/Natureza:

$<\ldots>$ na medida em que a exposição do absoluto inicia de sua identidade absoluta e passa para o atributo e daqui para o modo, nisso, ela percorreu completamente seus momentos. (p.198)

Na "Observação", Hegel estabelece a "deficiência" que a noção spinozista de substância tem, relativamente à sua noção de absoluto: ao contrário da noção hegeliana de absoluto, que admite uma reflexão de essência de caráter determinante, a noção spinozista de substância é pensada de modo tal que a reflexão de essência que ela admite fica restrita a ser "um pensar externo", a uma reflexão externa (p.200).

Por pensar externo, Hegel entende o pensar no qual a "substância não contém, ela mesma, a forma absoluta, e o conhecimento da mesma não é um conhecer imanente", que:

$<\ldots>$ não deriva da substância o que aparece como finito, a determinidade do atributo e do modo, assim com também em geral não compreende e não deriva da substância a si mesma, mas é, antes, ativa como um entendimento externo que acolhe as determinações como dadas e as reconduz ao absoluto, mas não extrai seus inícios a partir desse. (p.20o)

À primeira vista, portanto, pareceria que Hegel estaria tipificando a reflexão de essência constituinte da metafísica de Spinoza como uma reflexão exterior, a par da reflexão de essência da metafísica de Kant (ver Tabela 5).

Mas Spinoza é um filósofo pré-crítico, sua noção da substância Deus/Natureza é dogmática, concebida sem mais como estando além de toda experiência possível. Portanto, a reflexão de essência que constitui sua metafísica não pode ser a reflexão exterior, que tem molde kantiano.

Entendemos, assim, que é preciso diferenciar as expressões hegelianas "reflexão externa" e "reflexão exterior". Por reflexão 
externa devemos entender, não a reflexão exterior que determina o imediato dado por meio do termo médio, que resulta do silogismo realizado entre o imediato e a essência posta, mas o simples entendimento externo, que não "silogiza" as determinações do imediato, mas que simplesmente "as acolhe como dadas" (e, ao que nos parece, as acolhe muito ao modo empirista).

Assim, a análise da "Observação" de Hegel sobre a filosofia spinozista, bem como a determinação do absoluto, que Hegel apresenta no corpo principal do capítulo, se não confirmam, pelo menos não invalidam, o modo como tipificamos a reflexão de essência constituinte da metafísica de Spinoza: reflexão pressuponente e geradora.

Em contraste, a reflexão de essência da metafísica de Hegel é tipificada, por ele mesmo, como reflexão determinante.

\section{Conclusão}

A noção de reflexão de essência tem lugar central no desenvolvimento da noção de essência, na "Ciência da Lógica" de Hegel. É com base na diferenciação dos diversos tipos de reflexão de essência que Hegel caracteriza a reflexão de essência que vai constituir sua própria metafísica da essência: a reflexão determinante.

Desse procedimento metódico realizado por Hegel, extraímos a ideia de que não se muda o referencial filosófico de uma teoria qualquer, sem que haja impacto na lógica dessa teoria.

Assim, pensamos que uma questão de pesquisa interessante é a do impacto lógico da decisão althusseriana de substituir o referencial hegeliano do marxismo por um referencial spinozista.

Para contribuir ao procedimento de reposta a essa questão, o presente trabalho obteve como resultado a tipificação da reflexão de essência constituinte da metafísica de Spinoza como reflexão pressuponente e geradora. 
156 | Revista Opinião Filosófica, Porto Alegre, V. o9; No. 01, 2018

\section{Agradecimentos}

Aos Profs. Agemir Bavaresco e Federico Orsini, pelos comentários ao rascunho inicial deste artigo.

\section{Referências}

HEGEL, G. W. F. Ciência da Lógica - 2. A Doutrina da Essência. Vozes, Petrópolis, 2017.

HEGEL, G. W. F. Princípios de la Filosofia del Derecho. EDHASA, Barcelona, 1988.

LORD, B. Kant and Spinozism - Transcendental Idealism and Immanence from Jacobi to Deleuze. Palgrave Macmillan, London, 2011.

PEDEN, K. Spinoza contra Phenomenology - French Rationalism from Cavaillés to Deleuze. Stanford University Press, Stanford, 2014. 